\title{
Universalismo y latinoamericanismo
}

\author{
FRANCISCO MIRÓ QUESADA \\ Profesor Emérito de la Universidad Nacional Mayor de San Marcos, Lima
}

El presente artículo es testimonial. En él relato las experiencias que he vivido durante más de medio siglo viendo cómo nacía y se desarrollaba, en América Latina, la filosofía de mi generación. Mi testimonio no es el de un observador externo, sino el de un observador que ha participado en el proceso y que ha visto las cosas desde adentro. No puedo saber hasta qué punto soy objetivo en lo que relato, ni si soy justo o injusto con los filósofos que menciono o no menciono. Lo único que puedo decir es que soy sincero en todo lo que digo. Lo que relato no pretende ir más alla de las vivencias que he experimentado en mi carrera filosófica. Por eso, no me he preocupado de proceder de acuerdo al exigente rigor académico. En el texto que sigue no hago citas del libro ni de las páginas en las que se encuentra la opinión del autor sobre el cual estoy hablando, ni pongo al final la obligada bibliografía de libros, ponencias de congresos y artículos de revistas especializadas.

Las experiencias que relato son las que he vivido en relación a uno de los aspectos más característicos y originales del filosofar latinoamericano: $e l$ enfrentamiento de dos concepciones de lo que debe ser la filosofía auténtica en América Latina. Este enfrentamicnto se manificsta en la actitud de los integrantes de dos grupos. En uno de ellos están los «universalistas» y en el otro están los «latinoamericanistas». Según el primero, la filosofía auténtica consiste en filosofar sobre los grandes temas de la filosofía, considerados desde la perspectiva actual, tratando de hacer aportes personales, aunque sean modestos, que sean interesantes de acuerdo a los cánones imperantes en la comunidad filosófica occidental. Para los segundos, la filosofía auténtica consiste en meditar sobre nuestra propia realidad, señalando los grandes problemas que la afectan, denunciando las injusticias que sufren nuestros pueblos como consecuencia de la prepotencia de quienes los explotan nacional o internacionalmente, y presentar posibles maneras de superar esta situación.

Debido a que he sido testigo presencial del enfrentamiento entre universalistas y latinoamericanistas, desde sus primeras manifestaciones hasta el dia de hoy, he podido seguir paso a paso la singular contienda. El enfrentamiento comienza a mediados de la década de los cuarenta y se prolonga a través de tres generaciones: la primera está integrada por los filosofos de mi gene- 
ración, como Leopoldo Zea, Fernando Salmerón, Mario Bunge, Gregorio Klimowski, Ernesto Maíz Vallenilla. En la segunda hay pensadores que comienzan a publicar en la década de los sesenta, como Newton C. A. da Costa, David Sobrevilla, Ulises Moulines. La tercera generación está constituida por pensadores cuyos primeros representantes inician su actividad filosófica a partir de la segunda mitad de la década de los setenta, y son seguidos por otros que comienzan a publicar en la década de los ochenta, como León Olivé, Walter Beller, Raymundo Morado, Isabel Villoro, Ana Rosa Pérez Ransanz. En lo que sigue no distingo entre generaciones. El criterio que utilizo para hablar sobre los aportes de los integrantes de uno u otro grupo es cl de la amplitud y la creatividad de su obra y, sobre todo, la manera como pasan del análisis a una visión de síntesis filosófica.

Conocer personalmente y haber frecuentado a las principales figuras de ambos movimientos me ha permitido comprender las razones que los indujeron a enfrentarse y a negarse recíprocamente.

\section{El primer enfrentamiento}

El primer enfrentamiento del que fui testigo fue el que se produjo entre Leopoldo Zea y yo mismo. En 1946 recibi una carta de Francisco Romero, el filósofo latinoamericano que por aquellos días era la figura más importante del subcontinente. Casi todos los jóvenes que estábamos dando los primeros pasos en el estudio de la filosofía sentíamos por él una gran admiración. En su carta me decía que Leopoldo Zea, un joven filósofo mexicano, iba a pasar por Lima y que valía la pena conocerlo. Para todos sus admiradores un pedido de Romero era una orden. De manera que establecí contacto con Zea apenas llegó a la capital. Después de algunas palabras de saludo y cortesía comenzamos a hablar sobre lo que estábamos haciendo. Leopoldo me dijo que acababa de publicar su primer libro: Apogeo y Decadencia del Positivismo en México, y que estaba preparando Historia del Positivismo en América Latina. Aunque no vibré de entusiasmo con la noticia, me impresionó el hecho de que para escribir el segundo libro hubiera ido hasta Argentina para obtener datos de primera mano. Y que su viaje al Perú era también para obtener información en los textos de los filósofos, ideólogos y políticos peruanos.

Cuando me preguntó qué es lo que estaba haciendo, le dije que acababa de terminar de escribir un libro de lógica matemática de próxima publicación. Estaba convencido de que la noticia le iba a parecer interesante. Pero su respuesta me dejó perplejo. Me dijo que escribir sobre ese tipo de cosas era perder el tiempo. «Lo que debes hacer», continuó, «es escribir sobre la historia de la lógica en el Perú».

¿Qué podía responder ante aquella autoritaria afirmación? Sólo una cosa. ¿Cómo quieres que escriba la historia de la lógica en el Perú si esta lógica aún no cxiste? Primero hay que hacerla y luego escribir su historia. Pero Zea 
era monolítico. «Entonces -replicó- escribe sobre la lógica durante la Colonia.» Ante esta actitud comprendi que estábamos separados por un abismo infranqueable. Sin embargo, iniciamos una cordial amistad que con el tiempo se transformó en fraterna.

\section{Antittesis}

Algunos años más tarde fui invitado a un congreso mundial, organizado por la Federación Internacional de Sociedades de Filosofía, FISP, que coincidía con el IV centenario de la fundación de la primera universidad mexicana, que con el correr de los siglos se transformó en la prestigiosa Universidad Nacional Autónoma de México. Por ese entonces había avanzado algo en el conocimiento de la lógica, y las sesiones que más me interesaban eran las de filosofía de la ciencia. En una de esas sesiones escuché a un joven, más o menos de mi edad, que hablaba con una seguridad absoluta y con un conocimiento apabullante del tema que estaba desarrollando. Era Mario Bunge. Apenas terminó salió del salón, y aunque faltaban aún varias exposiciones, me levanté y lo seguí. Nos presentamos. Le expresé mi admiración por su ponencia, y cuando le dije que había publicado un libro de lógica matemática reaccionó en forma muy favorable y me pidió que le enviara un ejemplar (cosa que no hice, pues tenía miedo de que lo encontrase demasiado superficial). Desde ese día, como sucedió con Zea, iniciamos una amistad que no hizo sino crecer con el tiempo y llegó asímismo a ser fraterna.

Mario era exactamente la antítesis de Zea. Sólo le interesaba la filosofía rigurosa, y consideraba que escribir sobre la historia de la lógica en América Latina era perder el tiempo. Cuando hablaba, convencía. Y mostraba, sin proponérselo, que era capaz de hacer creaciones importantes en los más difíciles campos del filosofar. Para él, la filosofía auténtica consistía en conocer a fondo los grandes temas de la filosofía universal, pero de acuerdo con la época. La filosofía de nuestros días tenía una nueva manera de enfocar los temas tradicionales, utilizando métodos más rigurosos que los disponibles en el pasado. Había una comunidad filosófica occidental y nosotros debíamos pertenecer a ella, tratando de hacer aportes, hasta donde nos fuera posible, en los grandes temas, como la metafísica, la epistemología, la lógica, la ética. Mario y yo hablábamos el mismo lenguaje. En el mismo congreso conocí a Fernando Salmerón, pensador mexicano de primera línea, que tenía una orientación parecida, y a dos o tres filósofos de diversos países latinoamericanos que hablaban el mismo idioma. Y me di cuenta de que existía ya una generación de pensadores latinoamericanos que se había propuesto una meta: hacer filosofía auténtica.

Pocos años después conocí a Luis Villoro y a N. C. A. da Costa. El primero pertenecía al grupo slatinoamericanista» que había aglutinado Leopoldo Zea en torno suyo y que estaba creciendo rápidamente. Pero no pasó mucho tiempo antes de que se apartara del grupo y orientara sus investigaciones hacia la 
filosofia «universalista». Con el tiempo ha llegado a ser uno de los principales pensadores de América Latina. En cuanto a N. C. A. da Costa, basta decir que siendo aún muy joven creó un nuevo tipo de lógica sumamente importante, llamada «lógica paraconsistente», que se estudia hoy en todo el mundo. Y que con el tiempo, después de haber hecho numerosos aportes a la lógica, la epistemología y la filosofía matemática ha llegado a ser uno de los lógicos más famosos de la comunidad filosófica occidental.

\section{La licha de la autenticidad}

Pasaron algunos años más y ya era evidente que los filósofos latinoamericanos de mi generación tenían un proyecto definido: hacer filosofía auténtica. No cabc duda de que una de las motivaciones del proyecto era el complejo de inferioridad que, por el hecho de haber sido colonias, teníamos frente al pensamiento de occidente. Pero no era la única. La segunda era, simplemente, que ćramos jóvenes. En una conversación con Bertrand Russell y Alfred Ayer, en Londres, en la primavera de 1955, el primero me dijo que uno de sus ideales juveniles era ser invitado por universidades cxtranjeras y a congresos importantes. Sin embargo, lo dramático era, como hemos dicho, que había dos grupos definidos y contrapuestos en relación al concepto de filosofía auténtica. Traté de explicar a los dos en qué consistía esta división, y después de un buen rato Russell entendió más o menos de qué se trataba. «Comprendo la motivación de los latinoamericanistas - dijo-, mas no creo que el camino de la liberación cultural y política de América Latina sea el que han elegido.» Pero Ayer permaneció durante mi perorata completamente en la luna. «Para mí - dijo- - todo lo que he escuchado es puro non-sense.»

En los congresos, en los coloquios, en las conversaciones de pasillo entre sesión y sesión, el hiato se iba transformando en abismo. En un abismo de pura negación. Hablando con franqueza, puesto que se trata de dar testimonio, cada grupo detestaba al otro. Y ninguno reconocía los méritos del grupo contrario. Los que pertenecían al grupo universalista decian que los latinoamericanistas, a quienes llamaban los «políticos», no tenían ninguna formación seria en la filosofía teórica y que, por eso, no eran capaces de comprender lo que ellos (los universalistas) escribían. Los políticos retrucaban con la misma agresividad que los universalistas, a quienes llamaban «analíticos», diciendo que eran unos reaccionarios y que le hacían el juego al imperialismo al encerrarse en la torre de marfil de teorías inservibles e inaplicables a la realidad social. 


\section{Despertar situacional}

Los filósofos que había conocido, de ambos grupos, me enviaban sus libros, de manera que estaba más o menos al día sobre el filosofar latinoamericano. Por mi parte, seguía estudiando filosofía teórica, pasando de la lógica y la epistemología a la ética. Y quedé asombrado al comprobar que las tesis tradicionales de la filosofía moral podían invalidarse mediante sencillos contraejemplos. Descubrí así que el rigor adquirido mediante el entrenamiento en lógica y en matemáticas se podía utilizar con gran eficacia en cuestiones de ética y de filosofía política. Pronto comprobé la falta de rigor de las ideologías que, en aquella época, se disputaban la primacía, como el marxismo, la democracia cristiana, el liberalismo y el humanismo. Y la crítica ideológica me condujo hasta la visión frontal de mi propia realidad. Me di cuenta de que no conocía lo que verdaderamente era mi patria. Nunca se me había ocurrido pensar en que la realidad donde vivía y filosofaba, borracho de teoría, enamorado de Leibniz, de Kant y de los Principia Mathematica, era una realidad dramática escindida en dos partes, una de ellas pequeña y colmada de privilegios y la otra una inmensa mayoría de hombres y mujeres que vivían en la inopia y el desamparo. Una inmensa mayoría explotada y despreciada por el grupo privilegiado. $Y$ entonces comprendí que ellos también me ignoraban y me consideraban extranjero. En pocas palabras: que yo formaba parte de la oligarquía. Ante semejante situación, ¿qué debería hacer un filósofo? No había sino una respuesta: utilizar todos sus recursos intelectuales para contribuir, en la medida de lo posible, a restañar el desgarramiento que, desde la Colonia y la era republicana, sufría el Perú.

Tomada esta decisión, comencé a escribir en diarios y revistas y a hablar del tema en los congresos de filosofía en los que había secciones de trabajo sobre filosofía política. Pero sin descuidar mi interés por la filosofía teórica. Era esta última la que me había revelado la necesidad de meditar sobre nuestra propia realidad, y csta meditación me había conducido a la denuncia de la opresión y la injusticia. Por esta época había establecido contacto con un amplio grupo de filósofos latinoamericanistas. Abelardo Villegas, María Helena Rodríguez, Horacio Cerutti ${ }^{1}$, Jorge Portillo, Joaquín Sánchez Mac Gregor, en México. Arturo Roig, Gregorio Weinberg, Enrique Dussel, Mario Casalla, Juan Carlos Scanone, en Argentina. Arturo Ardao, en Uruguay. Joaô Cruz Costa, Darcy Ribeiro, en Brasil. Ricaurte Soler, en Panamá. Carlos Paladines, en Ecuador. Guillermo Hoyos, en Colombia. Ernesto Maíz Vallenilla, en Venezuela. En el Perú, por la misma época, frecuentaba a Augusto Salazar Bondy y, pocos años más tarde, a David Sobrevilla y María Luisa Rivara de Tuesta.

Maria Helena Rodríguez, esposa de Leopoldo Zea, y Horacio Cerutti son argentinos de nacimiento, pero la parte más importante de su obra se ha desarrollado en México, y creemos que no es inexacto considerarlos como pensadores mexicanos. 


\section{El documento de Morelia}

El pensamiento de Leopoldo Zea, a través de una obra prolífica, va ampliando su horizonte. De la filosofía de lo mexicano pasa a la filosofía de lo americano, y de la filosofía de lo americano asciende a la filosofía de la liberación. La evolución de su pensamiento tenía que desembocar en un planteamiento liberacionista. La idea central de Zea es exigir a los occidentales colonialistas, y luego imperialistas, que procedan con nosotros como procedieron con ellos mismos. A través de la historia el hombre de occidente va forjando una sociedad cada vez más libre, que hacia fines del siglo pasado desemboca en una democracia constitucional. En último término, la democracia europea puede considerarse como un humanismo en el que todo individuo debe ser considerado como un fin en sí mismo ${ }^{2}$. Sin cmbargo, conforme el humanismo y la democracia iban asentándose en Europa, los pueblos no occidentales eran colonizados por los ejércitos, que «representaban la libertad y la cultura» occidental. Y desde el segundo tercio del siglo pasado, Estados Unidos se va orientando hacia un imperialismo que termina por trascender el ámbito latinoamericano. Por eso, la filosofía de lo americano se amplió hacia una filosofía de la liberación. Porque los países sojuzgados por los occidentales estaban en las mismas condiciones que los nuestros. En Asia y África los países ex coloniales existian en forma similar a la nuestra. Y había intelectuales que se expresaban de manera semejante a los filósofos de lo americano, como Franz Fanon en Argelia y Abdel Malek en Egipto.

La filosofía de la liberación se fue perfilando cada vez con mayor nitidez. En la década de los setenta era ya un movimiento que se había extendido por toda América Latina y había alcanżado una vigorosa madurez. Esta madurez se expresa en un congreso de filosofía realizado en la ciudad de Morelia, México, en 1975. En este congreso me encontré con Leopoldo Zea, Arturo Roig, Abelardo Villegas y Enrique Dussel. Todos teníamos el mismo empeño: expresar los rasgos esenciales de la filosofía de la liberación. Con esta finalidad nos reunimos varias veces durante largas horas, tratando de llegar a un acuerdo que contuviera una visión clara y a la vez orientadora de esta filosofia. Los cinco estábamos de acuerdo sobre la función que debía desempeñar la filosofía en países como los nuestros y en cualquier región del mundo. Esta función no era otra que contribuir a la liberación de las grandes masas que vivían en el abandono y la opresión.

"Desde luego estamos generalizando, pues la conquista de la libertad democrática, fundada en principios bumanistas, sólo se alcanza después de luchas, muchas veces cruentas, contra las clases dominantes. Pero a pesar de la ruta zigzagueante que sigue el hombre occidental, cuando a veces parecía que todos los avances se habían perdido, lograba superar las resistencias, tanto inerciales producidas por las instituciones sociales como dinámicas generadas por la oposición de las clases privilegiadas. 
Pero cuando comenzamos a redactar el documento surgicron algunas discrepancias. Zea, Villegas y Roig pertenecían al grupo de los "políticos». Y aunque Dussel tenía una concepción muy complicada de lo que debía ser la filosofía de la liberación, hablaba más o menos el mismo lenguaje, cuyo fundamento teórico era la dialéctica ${ }^{3}$. En cambio yo era una especie de paracaidista in partibus infidelium. Porque a pesar de que, de manera inequívoca, yo denunciaba los mismos males que ellos denunciaban, lo hacía en un lenguaje diferentc. Debido a esta diferencia de lenguaje los integrantes del grupo me consideraban un "analítico», pero tenían que aguantarme, pues los cinco perseguíamos los mismos fines, y además sabían que yo me había enfrentado decididamente a los analíticos, algunos de ellos feroces, en múltiples oportunidades, defendiendo la autenticidad de la filosofía latinoamericanista. Para mí, la palabra dialéctica tenía un sentido sumamente vago, y por eso no era conveniente fundar la estructura teórica en un concepto que nadie sabía con certeza lo que significaba ${ }^{4}$. Mi punto de vista estaba centrado en el análisis lógico. En lugar de recurrir a una serie de conceptos vagos para fundamentar la filosofía de la liberación era necesario recurrir a un pensamiento claro que, partiendo de la premisa fundamental de la filosofía de la liberación, a saber, la forjación de una nueva sociedad de la que se hubiera desterrado para siempre la explotación del hombre por el hombre, se dedujeran con rigor las consecuencias. $Y$ estas consecuencias no podían ser sino una: cl socialismo libertario. Para llegar a la sociedad sin clases los «políticos» seguían dos vías posibles: o llegaban de manera ingenua, sin preocuparse demasiado por cl fundamento teórico, o llegaban de manera complicadísima, que impedía una comprensión clara del razonamicnto efcetuado. La vía que yo proponía consistía en partir del principio fundamental de la ética kantiana: toda persona debe ser considerada como un fin en sí mismo. De este principio se podía deducir con rigor que la meta de la historia era la sociedad sin clases ${ }^{5}$.

"Enrique Dussel habia creado un método que, según su criterio, era superior al dialêctico: el método analéctico. Pero fuera de que el método se desarrollaba y aplicaba dentro del mismo espíritu de la dialéctica hegeliana y marxista, sólo que era mucho más complicado, no creo que cometa una injusticia al considerarlo como un filósofo dialectico. Esta discrepancia no significa que no tenga el mayor respeto por su posición, ni que no admire su impresionante información respecto del filosofar helénico-occidental.

* En aquella época ya existían diferentes concepciones de la dialéctica, como la de Dubarle, Apostel, Cecik, Petrov, para no citar sino unos cuantos entre la multitud de filósofos que han intentado desarrollar un sistema dialéctico aplicable al conocimiento de la tealidad. Sin embargo, a partir de la década de los ochenta la situación se va haciendo menos vaga y algunos autores, como Hegselman y, sobre todo, Batens, logran, con una gran complicación, desarrollar sistemas que pueden considerarse precisos. El gran desafio de la dialéctica es el hecho de que, conforme avanza el conocimiento de manera dialéctica, las reglas de la inferencia deben ir cambiando, pero de manera racional, es decir, no arbitrariamente, sino como una consecuencia del propio desarrollo dialéctico.

s Cuando en esa época hablaba de las sociedades sin clases, nunca pensé que esta sociedad debía organizarse totalitariamente, a lo Stalin o a lo Mao-Tse Tung. La sociedad sin clases debía 
Estas discrepancias crearon un serio desacuerdo en la redacción final de la declaración: los cuatro filósofos «políticos» insistían en que apareciera el término «dialéctica» varias veces en el documento, y se oponían a que apareciese la palabra «análisis» por considerar que se trataba de un término utilizado por los filósofos reaccionarios. Yo insistía en que, además de todas las veces que se mencionara a la dialectica, se mencionase, aunque fuera una sola vez, la palabra «análisis». Después de varias horas de discusión quedaron incorporados los dos términos, y aunque la dialéctica se mencionaba varias veces, figuraba también el análisis (aunque sólo una vez, lo que consideré un gran triunfo). Por otra parte, me parecía exagerada la excesiva referencia al imperialismo, como si todos nuestros males se debieran al vecino del norte y ni uno sólo a nosotros, salvo los producidos por las oligarquías nacionales, aliadas del imperialismo.

A pesar de todo, creo que la importancia del documento reside en el hecho de que la Declaración de Morelia muestra el interés que tenía un grupo numeroso de filósofos latinoamericanos en la transformación de nuestra realidad social. Y, además, porque era un hecho innegable que la fundamentación de base para alcanzar dicha transformaciôn, cuya meta última era, y sigue siendo, la humanización del mundo, se podía hacer utilizando los métodos rigurosos y simples de la lógica formal.

\section{Los «analíticos» ${ }^{6}$}

Conforme la filosofia de lo americano se iba desarrollando, los universalistas iban haciendo contribuciones cada vez más interesantes. Entre los trabajos que los «analíticos» inician a finés de la década de los cuarenta y los que van apareciendo hasta la década de los ochenta se descubre un progreso sin pausa. Puede afirmarse, sin ningún tropicalismo, que el gran proyecto que los motivó y dio sentido a toda su producción, se había cumplido. Hacia los inicios de dicha década el pensamiento latinoamericano había hecho aportes creativos comparables a los que, durante el mismo lapso, se hacían en cualquier parte del mundo. Los trabajos de buen nivel constituían una apreciable cantidad y los auténticamente creadores no eran escasos. Empezando por Mario Bunge, que es, sin duda, el pensador más completo y más creativo de nuestra generación, siguen pensadores que pertenecen tanto a su generación como a otras más

ser una sociedad libre y democrática. Hoy pienso que los planteamientos clasistas han perdido popularidad. Sin embargo, en América Latina aún tienen un sentido concreto, pues las condiciones existenciales de nuestras poblaciones no son como las europeas o las norteamericanas. Pero estoy convencido de que en el futuro, en caso de que se utilice la tecnología en una buena dirección, es decir, que sea hecha para favoreccr a los ciudadanos y no para manejarlos como títeres, el mundo será mucho mejor. Si alguien me acusa de ser demasiado optimista responderé paladinamente que, por supuesto, lo soy.

"Algunos de los filósofos que cito han fallecido. 
jơvenes. Debemos citar entre otros, por su rigor y su creatividad, los siguientes: Frondizi, Klimovski, Alchourrón, Bulygin, Castañeda, Rabossi, Orayen, Olivé, Salazar Bondy, Li Carrillo, Canabrava, Sobrevilla, Cordero, Secada, Sosa, Gracia ?

\section{Guerra en dos frentes}

Según Bismarck, el Canciller de Hierro, un pais nunca debe hacer una guerra en dos frentes. Guardando las distancias, tuve que dar una batalla bifronte: contra los «analíticos" y contra los «politicos», Cuando comencé a dar argumentos en ponencias de congresos y en artículos de revistas, tratando de demostrar que los «políticos» estaban haciendo filosofía auténtica, los «analíticos» se me echaron encima, tildándome de dejarme llevar por la amistad y ampliando el campo de la autentícidad filosófica de manera inaceptable. De acuerdo a tu criterio, me decian, todo puede ser filosofía auténtica. A veces las discusiones fueron tan fuertes que nos decíamos cosas desagradables. Pero los ataques de los universalistas no eran nada comparados con la saña de los latinoamericanistas. Para mí fue una experiencia muy interesante que traté de interpretar de la siguiente manera. Los «políticos» eran intelectuales comprometidos. Durante las décadas de los scsenta y setenta era casi imposible ser un filósofo político sin sentirse comprometido a fondo en la lucha por la liberación, tanto cxterna (batalla contra el imperialismo) como interna (batalla contra las oligarquías aliadas del imperialismo). Por eso, sinceramente, los «políticos» sentían que el filósofo auténtico tenía una misión sagrada y que todo filósofo que no se interesase por la liberación de nuestros pueblos era un débil que rehuía sus responsabilidades.

Nunca olvidaré un enfrentamiento que tuve, durante un coffee-break, en un congreso de filosofía que se estaba realizando en México con tres filósofos «políticos». La conversación, como era frecuente en aquellos tiempos, recayó sobre el enfrentamiento entre los «analíticos» y los «políticos». Cuando me referí, con admiración, a un universalista $A$, uno de mis interlocutores me espetó: «El filósofo $\mathrm{A}$ es un cobarde. iCómo puedes creer que es supcrior a $B$ (que estaba sentado frente a mí), que ha tenido un comportamiento heroico y que, debido a haber denunciado a los opresores de su país, los esbirros trataron de asesinarlo y tuvo que exiliarse en un país extranjero?» El comportamiento de $\mathrm{B}$ había sido, efectivamente, heroico, y todos lo admirábamos por su coraje y la autenticidad de su compromiso. Además, era muy respetable como filósofo. Pero al escuchar hablar así de A se me subió la sangre y le

'Aunque Castañeda, Sosa y Gracia han hecho su carrera filosófica en los Estados Unidos, el primero nació en Guatemala y los últimos nacieron en Cuba. Este hecho basta y sobra para considerarlos de los nuestros. En estos casos considero que se debe aplicar tanto el jus soli como el jus sanguinis. 
repliqué: "Tú no puedes hablar nada contra los "analíticos", porque ni siquiera los entiendes.» $\mathrm{Y}$ mientras $\mathrm{C}$, joven «politico» brillante que estababa con nosotros, se eclipsaba con prudencia, siguió la discusión a gritos con ajos y cebollas. Por supuesto, a la media hora éramos más amigos que nunca.

Pero el hecho es que yo estaba en ambos grupos, y lo estaba porque nunca se me ocurrió pensar que sólo uno de ellos tenía la razón. Como sucede casi siempre, con el tiempo las cosas se han suavizado. Hoy día los «políticos» y los «analíticos» se toleran y hasta se invitan a los congresos organizados por cualquiera de los dos grupos. Hegel tiene razón cuando dice que después de la lucha viene la reconciliación.

\section{Diagnóstico: la filosofia latinoamericanista}

Como he dicho, durante los cuarenta años en que la filosofía latinoamericana, es decir, la filosofía que se hace en América Latina ${ }^{8}$, logra alcanzar un alto nivel se han hecho aportes valiosos en ambos campos: el de la filosofia práctica y el de la filosofía teórica. Pero ¿en qué consisten estos aportes? Es imposible en un texto como el presente entrar en detalles, por eso me limitaré a los rasgos más visibles de nuestra producción filosófica. Comencemos por los aportes de la filosofía latinoamericanista. Creo que sus principales aportes son los siguientes: 1) Difundir un aspecto importante del filosofar latinoamericano tanto en Europa como en los Estados Unidos, África y Asia. 2) Mostrar la relación de la filosofía con el mundo social en que se hace. 3) Haber insistido en que un filósofo debe ser un intelectual comprometido. 4) Decir que este compromiso no sólo consiste en denunciar la injusticia y atacar el imperialismo allí donde se encuentren, sino que debe contribuir, de acuerdo a sus posibilidades y de manera coherente, es decir, libertaria, al proceso de transformación.

No cabe duda de que la filosofía de la liberación ha dado varias veces la vuelta al mundo. Y tampoco puede negarse que se trata de un movimiento original que no se ha producido en ningún otro continente. Hegel consideraba que la función del filósofo debía reducirse a interpretar el espíritu de su tiempo (Zeitgeist). Marx, en cambio, considera que la filosofía puede y debe ser un proceso de liberación. La Weltanschauang de un filósofo depende de su posición de clase. Si pertenece a la clase dominante será una visión conservadora y, casi siempre, reaccionaria. Pero, sigue diciendo Marx, hay intelectuales que han sido capaces de captar el sentido de la historia y entonces apoyan el movimiento de los explotados. Se une así la filosofía con la revolución del

\footnotetext{
"Arturo Ardao, en un excelente libro sobre diferentes tópicos dedicados a la historia de las ideas, aclara el sentido que puede tener la filosofía de to americano. De un lado, sfilosofía latinoamericana» significa filosofía sobre América Latina. De otro lado, significa la fillosofia que se hace en América Latina.
} 
proletariado. La filosofía es el cerebro de la revolución y el proletariado es el ariete. Es la fuerza que destruye la estructura social forjada por el grupo dominante. En este sentido no puede negarse que el marxismo es una filosofia de la liberación. Sin embargo, el pensamiento de Marx es etnocéntrico y dogmático. Aplicando ad pedem litterae su teoría a la realidad mexicana, celebra la invasión norteamericana que se apodera de casi la mitad del país porque, de esta manera, la revolución proletaria se realizaría inevitablemente. La filosofía de lo americano y luego, en forma más general, de la liberación, no acepta limitaciones etnocéntricas y es, por eso, en contra de lo que creían los universalistas, y de lo que siguen creyendo todavía algunos de ellos, una filosofía verdaderamente universal. Por otra parte, la filosofía de la liberación no es un movimiento marxista ${ }^{9}$. Algunos de sus principales integrantes han sido influenciados por el marxismo, pero no son marxistas sensu stricto. Es por eso una filosofía original, una de las muchas pruebas de la creatividad del pensamiento latinoamericano. Es cierto que, como dicen sus críticos, muchos filósofos de la liberación carecen de rigor académico. Pero lo que importa es el sentido del movimiento, que avanza hacia una meta que es fundamental. Por otra parte, hay textos de los más importantes representantes del movimiento que despliegan panoramas notables sobre la manera como se han utilizado ideas filosóficas occidentales para afianzar el poder de las clases dominantes. Y por último, importantes filósofos universalistas de alto rigor académico han adoptado posiciones que coinciden en puntos esenciales con la filosofía de la liberación, como, por ejemplo, Augusto Salazar Bondy en el Perú y Luis Villoro en México ${ }^{10}$.

Ha pasado casi una década del derrumbe de la Unión Soviética. Y las cosas han cambiado vertiginosamente. La época del gran auge de la filosofía de la liberación fue entre la década de los sesenta y la de los ochenta. Pcro el hecho de que el comunismo soviético se transformó del sueño de todos los revolucionarios del mundo en la pesadilla de una farsa sangrienta, ha planteado un fuerte desafío a los "políticos». Para mí, desde el punto de vista ideológico, el derrumbe de la Unión Soviética no significó ninguna necesidad de cambiar mis puntos de vista. Porque fuera de que lo había predicho con

${ }^{7}$ La sociedad sin clases es uno de los principales integrantes del pensamiento de Matx y de los marxistas. Pero la idea de la sociedad sin clases es anterior al marxismo. En algunas utopias, como en la de Tomás Moro, en el pensamiento de algunos revolucionarios durante la Revolución Francesa, como Babeuf, y en algunos socialistas utópicos, especialmente en Fourier, la idea de la sociedad sin clases como condición de la felicidad social sc encuentra claramente expuesta.

"Desgraciadamente la muerte prematura de Salazar Bondy, que era filósofo analítico, miembro distinguido del grupo latinoamericanista, y estaba comprometido a fondo con las ideas revolucionarias del movimiento, terminó con una trayectoria que habria influido favorablemente tanto en el nivel académico como en las metas fundamentales de la filosofía de la liberación. 
treinta años de antipación ${ }^{11}$, nunca había dicho que la revolución social sólo podría llevarse a cabo por medios violentos. Pero era evidente que la mayor parte de los «políticos» debían estar en gran desconcierto. Por eso aproveché una invitación para asistir en Guadalajara (México) al homenaje que sc iba a rendir al macstro Lcopoldo Zca, que había cumplido ochenta años. Y presenté una ponencia titulada «Filosofía de la Liberación-Reajuste de categorias».

En ella decía que desde que se inició cl movimiento latinoamericanista habían pasado más de treinta años, y que en un lapso semejante siempre se producen procesos imprevistos que pueden cambiar el contenido del panorama histórico. El cambio más grande que se había producido era el derrumbe del poder soviético. Y que ante este hecho teníamos que hacer cambios definidos en nuestras categorías ideológicas. La meta última de la filosofía de la liberación era, por supuesto, intangible: la sociedad sin clases. Pero lo que sí debía cambiarse era la metodología. Porque había un hecho que no podía ignorarse: la experiencia histórica nos había enseñado que había una relación difícil de precisar, pero innegable, entre la democracia formal y el capitalismo. De manera que parecía difícil llegar a una auténtica sociedad sin clases organizando la economía de acuerdo a las pautas del socialismo. Algo semejante estaba ocurriendo con el socialismo europeo. Sólo que este socialismo se distinguía muy poco de un capitalismo mitigado por algunas leyes sociales más o menos avanzadas. La conclusión era inevitable: para que la filosofía de la liberación pudiera remozarse y seguir influyendo en el mundo de la filosofía política debía saber que era imposible eliminar al capitalismo de un plumazo. Y debía, además, tener conciencia de que la democracia formal era una condición necesaria de la democracia como estilo de vida.

Pero, además, debía hacer frente a un problema fundamental. Popper ha señalado con acierto que querer imponer un modelo determinado de sociedad derivado de una teoría filosófica era ir a un necesario fracaso. Porque la sociedad es una realidad que no se deja amoldar por un sistema conceptual. Por eso, querer imponer un modelo apriorístico de cstructura social es caer indefectiblemente en el totalitarismo. Y esto significa que ninguna filosofía, y entre ellas la filosofía de la liberación, debe afanarse por la imposición de un modelo. Sin embargo, el problema puede ser resuelto de la siguiente manera. Una cosa es la meta y otra muy distinta es el modelo. La meta de la sociedad sin clases es inamovible. Sin ella la filosofía de la liberación se derrumba. Mas para llegar a la meta se debe proceder de manera pragmática.

De inmediato surge la pregunta: ¿Qué significa la expresión de «manera pragmática»? Puede significar muchas cosas, entre ellas que se puede implantar un régimen de tiranía si con este régimen se puede llegar a la sociedad sin clases. Pero ya estamos vacunados contra este cuento. Por eso, el pragmatismo

"En mi libro La otra mitad del mundo, que publiqué en 1959, a mi retorno de un viaje a la Unión Soviética y China Popular, digo que la peor crítica del comunismo habría de salir de la propia Unión Soviética y que su derrumbe era inevitable... 
debe estar encuadrado dentro de pautas muy bien definidas. $Y$ estas pautas son claras: avanzar siempre de manera coherente. En nombre de la libertad no se pueden hacer reformas que la anulen o la limiten. Se debe ser, además, muy prudentes con las medidas económicas. El Estado debe dar leyes que favorezcan económicamente a las mayorias. Sobre todo debe ser muy severo y muy técnico en la aplicación y cobranzas de los impuestos. Y aunque caiga en un lugar común, debo decirlo: no se puede matar a la gallina de los huevos de oro. Un exceso de impuestos detiene de inmediato el interés de los empresarios por invertir. Pero por otra parte, debe perseguirse la democracia directa. El ejercicio del poder popular no debe limitarse a las clecciones de presidentes, representantes y alcaldes. Debe poder ejercerse en relación a muchos organismos estatales, paraestatales y municipales. $Y$ esto es muy importante, el pueblo debe tener poder revocatorio en relación a todas las investiduras. En los países con régimen parlamentario la revocación existe en la práctica. Pero en los países con regímenes presidencialistas la revocación puede ser peligrosa porque puede conducir al caos. Sin embargo, podría hacerse realizando un referéndum cuando la administración presidencial hubiera llegado a la mitad de su gestión. Para lograr la máxima intervención del pueblo en las decisiones que puedan afectarlo deben aprovecharse los enormes recursos de control y de decisión que ofrece el progreso de la informática. En algunos países se está aplicando con éxito cada vez mayor. En varios países, entre ellos el Perú, se ha creado la figura del Ayuntamiento Cibernético, que permite a los ciudadanos que están bajo la autoridad de un municipio distrital, hablar directamente con el alcalde desde sus propias casas, para expresar su opinión sobre cualquier asunto que pueda afectarlos de una manera u otra. De acuerdo con la experiencia puede decirse, sin temor de errar, que mientras haya mayor democracia directa la diferencia de clases será cada vez menor y el progreso económico será cada vez mayor.

Si se comienza a analizar en detalle el proceso de avance pragmático hacia la meta final se descubrirán mil dificultades. Porque no hay nada que resista al casuismo, ni siquiera la lógica formal. Pero la casuistica limita sin destruir el principio general. A pesar de las dificultades sin nombre que habrán de hallarse en el camino hacia la sociedad sin clases, no hay ninguna razón para creer en la imposibilidad de su realización. Utilizando la técnica de manera coherente, se puede avanzar muchísimo hacia una sociedad en la que no existan clases dominantes y clases dominadas. Clases, desde luego, que entren en conflicto respecto de sus intereses. Decir que ya terminó la lucha de clases es ser ciego o hipócrita. La lucha de clases existe en los países democráticos, sólo que el enfrentamiento es democrático. Porque se manifiesta a través del pliego de reciamos. Una persona que juzga la lucha de clases de acucrdo a las pautas marxistas y leninistas dirá que reducir la lucha de clases al pliego de reclamos es una farsa, porque los trabajadores no consiguen ninguna ventaja. Pero se equivocan, porque en donde no podían lograr ninguna ventaja era 
precisamente en los países totalitarios. En cambio, en los países democráticos es una realidad que mediante el pliego de reclamos, resueltos de manera inteligente por la administración privada y, en último término, por el Estado, la clase trabajadora va aumentando cada vez más su nivel socioeconómico. $Y$ por último, si la tecnología es bien manejada, es indudable que habrá de crear condiciones de productividad aún no soñadas y que las clases irán desapareciendo paulatinamente. ¿Adónde se llegará? ¿Cómo será la organización social en el año 2100 ? Nadie lo sabe. Pero lo que sí se sabe es que si no volamos por los aires debido a un experimento mal hecho en algún laboratorio importante o en uno informal de aficionados, todo va a ser diferente. Y que esta diferencia, si se ha producido en una sociedad democrática, consistirá en un aumento muy grande del bienestar social.

\section{Diagnóstico: la filosofía universalista}

En América Latina está sucediendo lo mismo que en los países tecnológicamente más avanzados: hay filósofos que han hecho aportes que vale la pena conocer. Pero como se oye decir con frecuencia, ya no hay nadie capaz de crear los grandes sistemas del pasado. Los tiempos de Leibniz, Spinoza, Kant, Hegel, Marx, Comte, Stuart Mill pasaron para siempre. Tal vez el último mohicano de Ios grandes creadores filosóficos es Husserl. Estoy de acuerdo con esta opinión, por el momento.

Quienes sostienen la tesis de la pobreza filosófica son, por lo general, los escépticos, los que creen, como los posmodernos, que la filosofía se ha reducido a ser una conversación interesante. Estos pensadores consideran que es imposible hacer filosofía comparable a lá que hicieron los grandes filósofos mencionados. La experiencia histórica nos ha enseñado que todo gran sistema filosófico es una construcción efímera de la mente humana. Quienes así piensan no se han dado cuenta de lo que realmente está sucediendo en la filosofía de nuestros días. Lo que está pasando en el lapso transcurrido desde la creación de la lógica matemática por Boole, De Morgan y, algunas décadas más tarde, en forma mucho más evolucionada, por Frege y Peano es que, gracias a los extraordinarios recursos de formalización y, en consecuencia, de análisis conceptual que nos brinda la lógica moderna, se han abierto campos insospechados de posibilidades analíticas. Este poder analítico permitió darse cuenta de que el análisis de los conceptos filosóficos básicos, expresado mediante lenguajes no formales, había sido muy limitado en la filosofía clásica. Desde luego nunca dejaremos de admirar a los grandes filósofos clásicos, ni de reconocer que si no hubiera sido por ellos la filosofía actual nunca podría haber cxistido. Pero los hechos son innegables. Un cstudiante universitario de filosofía, utilizando los actuales recursos formales, puede hacer análisis más profundos que cualquiera de los grandes filósofos clásicos. Porque el novato está sentado sobre un brazo de palanca mucho más largo que el que podían utilizar los 
clásicos. El único que se salva es Leibniz. Porque fue el primero en darse cuenta de la importancia del lenguaje para poder avanzar con seguridad por la vía del conocimiento racionalmente fundado. Pero Leibniz se habia adelantado dos siglos a su época.

Los asombrosos avances que se pudieron hacer con los nuevos recursos analíticos, como la creación de las lógicas modales, de las lógicas polivalentes, la demostración del teorema de Gödel y otras creaciones de enorme profundidad, abrieron un panorama inmenso a la investigación filosófica. El éxito de los métodos formales indujo a algunos filósofos como Russell, Ramsey $\mathrm{y}$, algunos años más tarde, Wittgenstein a analizar los conceptos y las gramáticas de los lenguajes naturales. Este análisis, que pronto se expandió como reguero de pólvora, permitió hacer nuevos enfoques de los temas clásicos y adentrarse en terrenos que ni siquicra fueron sospechados por la filosofía tradicional. Ante los nuevos planteamientos analíticos los conceptos clásicos resultaban superficiales. Conceptos como verdad, verdad empírica, verdad apriorística, verdad analítica, verdad lógica, axioma, regla de inferencia, teorema, sintaxis, semántica, contexto, proposición, enunciado, clases de enunciados como los ilativos y los performativos, y la rclaciôn entre una proposición y lo que piensa sobre su verdad quien la emplea (actitudes proposicionales), el significado de las normas éticas, jurídicas y políticas, de las expresiones interrogativas, de las expresiones poéticas, etc., constituyen un enriquecimiento temático espectacular. El esfuerzo intelectual que han debido hacer los filósofos que realizaron esta descomunal cantidad de análisis de los lenguajes formales y de los lenguajes naturales, que se ha desenvuelto durante casi un siglo, es una hazaña grandiosa de la inteligencia humana de todos los tiempos. Es asombroso que personas con una cultura filosófica universitaria no se hayan percatado de este hecho sin precedentes.

Pero no hay análisis sin síntesis. Como Kant ha dicho, pensar es unir. Por eso, la síntesis es inevitable después del análisis. Una vez que el análisis nos ha conducido a una altura de conocimientos filosóficos insospechados por los clásicos, ha de venir una síntesis, una síntesis mucho más amplia que las anteriores. Pero hacerla será en verdad difícil, porque para desarrollarla se debe dominar a fondo la riqueza temático-analítica disponible. Por eso, la filosofía se ha vuelto hoy día difícil, muy dificil. Pero si no se logra hacer una síntesis bien estructurada entonces, como sostienen los escépticos, la filosofia dejará de ser creadora y se reducirá a ser una cantaleta repetitiva.

Es obvio que la sîntesis, es decir, la organización en un sistema que abarque los resultados del proceso de análisis que hemos descrito, será cuestión de tiempo y habrá de hacerse a través de dos o tres generaciones. Sin embargo, hay ya sintomas alentadores de que la síntesis que debe realizar la filosofía está comenzando y que está más avanzada de lo que podría creerse. Y lo más significativo para nosotros es que una buena parte de dichos síntomas se cstán presentando en la filosofía hispanoparlante. 
Me siento muy incómodo por lo que voy a decir, porque me voy a referir a la obra de cuatro personas y estoy seguro de que hay más que merezcan ser citados. Lo que sucede es que los primeros son pensadores con cuya obra estoy familiarizado, y por eso puedo hablar en terreno firme. Pero hay una serie de pensadores españoles y latinoamericanos importantes que pueden estar siguiendo la misma vía hacia una filosofía de síntesis. He leído algunos de los libros y ensayos que han escrito los que me parecen más importantes. Pero desgraciadamente no he leído todo lo que debiera haberlo hecho para atreverme a dar una opinión fundada sobre su obra.

El filósofo del mundo ibérico y latinoamericano que, en mi opinión, ha avanzado más en el esfuerzo de síntesis es Mario Bunge. Su libro Basic Philosophy es un verdadero sistema fillosófico, en el que se desarrollan los temas usando los recursos de los lenguajes formales, pero también se recurre a los resultados del análisis de los lenguajes vernaculares. En este libro, del cual ya se han publicado nueve tomos, se abordan todos los grandes temas de la filosofía tradicional, como los supuestos metafísicos sobre los que se fundamenta toda la obra, la lógica, la metalógica, los metalenguajes, tanto los metamatemáticos como los semánticos, la teoría del conocimiento, la epistemología, la ontología, la ética, la psicologia, el derecho. De acuerdo a lo expuesto, en Basic Philosophy se encuentra una versión panorámica y a la vez detallada de un sistema filosófico. Desde luego la obra tiene errores, y algunas (muy pocas) de sus partes no calan muy hondo. Pero lo que debe llamarnos la atención no es que Bunge haya cometido errores, sino que haya cometido tan pocos. Por otra parte, los textos poco profundos de su obra, como, por ejempio, ol capítulo dedicado a la lógica, estấn ampliamente compensadas por la profundidad de muchas partes del libro, como la dedicada a la ontología (The furniture of the world), la dedicada a la epistemología, al concepto de estructura social y otras más. No creo equivocarme si afirmo que Mario Bunge es el gran pionero de la síntesis filosófica, que será el leitmotiv de la filosofía del siglo XxI.

Newton da Costa, además de haber creado un nuevo tipo de lógica que ha contribuido a romper el paradigma de la lógica clásica, ha demostrado recientemente que el teorema de Göbel es aplicable también en la física teórica. Esta relación se sospechaba, pero nadie lo había demostrado. No cabe duda de que su demostración constituye un paso muy importante en relación a la síntesis que debe hacerse de los resultados obtenidos en la filosofía analítica.

Luis Villoro cstá desarrollando un sistema filosófico que abarca los grandes temas centrales, tanto en su aspecto teórico como cn su aspecto praxeológico. Partiendo de la fenomenología, evoluciona hacia la filosofía analítica y aborda temas vertebrales del filosofar contemporáneo. Desarrolla una epistemología, una ética y coincide con los puntos centrales de una filosofía de la liberación, aunque sin mayores vínculos con el movimiento encabezado por Zea. Y hasta donde llega mi información, es el primer filósofo analítico en haber concebido y escrito una filosofía de la historia. 
Ulises Moulines está desarrollando un nuevo tipo de epistemología de la física. Se trata de una nueva visión de lo que realmente es una teoría física, cuyo pionero es el filósofo norteamericano P. Suppes. Pero la concepción de Suppes tenía serias limitaciones que era necesario superar. Ulises Moulines es uno de los filósofos que más ha avanzado en la creación de una nueva visión epistemológica de la física. Por otra parte, se interesa en cuestiones de ética y de estética. Cumple así el criterio de síntesis que revela el intento de organizar e integrar los resultados del análisis.

\section{Epílogo}

El futuro desarrollo de una disciplina cognoscitiva lógico-matemática o empírica (sea natural, sea social) es impredecible. De manera que lo que voy a decir puede considerarse como un wishful thinking. ¿Por dónde me gustaría que avanzara la filosofía latinoamericana en el siglo xxi? Me gustaría que avanzara hacia una visión sistemática y sintética de la realidad en sus aspectos vertebrales. $Y$ estoy convencido de que la única manera en que dicha visión pueda desarrollarse es replanteando el problema del conocimiento racional sobre nuevas bases. Pero este replanteamiento sólo podrá hacerse si la filosofía se funda de nuevo, es decir, mediante una radical autofundamentación. Esta autofundamentación es la única que permitirá unir el conocimiento teórico con la sabiduria, es decir, con una moral basada en la dignidad, la libertad y la creatividad humanas. Si no lo hace en los años venideros la filosofía quedará reducida, como quisieran los escépticos, a una «conversación interesante». Este proceso puede demorarse muchos años antes de que se transforme en paradigma del nuevo pensamiento filosófico. Pero si no estoy errado en lo que he dicho en las líncas que anteceden, el proceso ya está empezando. 


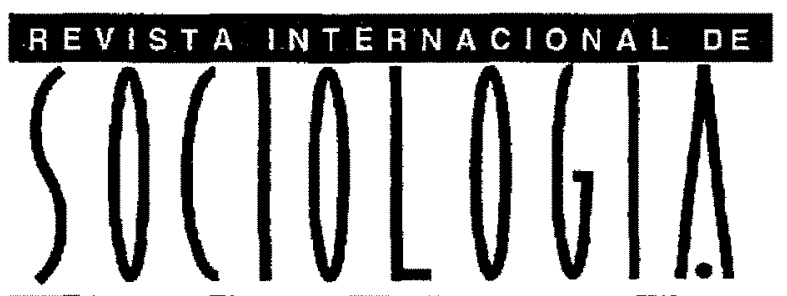

INSTITUTO DE ESTUDIOS SOCIALES AVANZADOS

TERCERA EPOCA - N2 21 - SEPTIEMBRE-DICIEMBRE, 1998

\begin{tabular}{|c|}
\hline ESTUDIOS \\
\hline $\begin{array}{l}\text { ELEMENTOS SOCIOLÓGICOS DE LA CONSCAIPCIÓN } \\
\text { FIDEL MOLINA LUQUE }\end{array}$ \\
\hline $\begin{array}{l}\text { LOS SISTEMAS DE PROTECCIÓN SOCIAL EN EUROPA } \\
\text { MANUEL HERRERA }\end{array}$ \\
\hline $\begin{array}{l}\text { PERCEPCIÓN SOCIAL DE LA CIENCIAY LA TECNOLOGIA EN ESPAÑA } \\
\text { VIDAL DIAZ DE RADA, PEIO AYERDIY MIKEL OLAZARAN }\end{array}$ \\
\hline $\begin{array}{l}\text { SOBRE EL USO GONJUNTO DE PRÁCTICAS CUALITATIVAS Y CUANTITATIVAS } \\
\text { JAVIER CALLEJO GALLEGO }\end{array}$ \\
\hline NOTAS \\
\hline $\begin{array}{l}\text { QUIEBRASY CONTINUIDADES EN LA SOCIALIZACIÖN. UN ANALLISIS DE LA OPCIÓN } \\
\text { LINGUISTICA EN LOS UNIVERSITARIOS DEL PAIS VASCO } \\
\text { BEGONA ABAD, GABRIEL GATTI INAAKI MARTINEZ DE ALBENIZ }\end{array}$ \\
\hline $\begin{array}{l}\text { LOS RIESGOS IDEOLOGICOS DEL CONFLICTO DEL AGUA EN ARAGÓN } \\
\text { JOSE ANGEL BERGUA }\end{array}$ \\
\hline $\begin{array}{l}\text { NACIÓNY LENGUA. REEXAMEN DE UN VIEJO MARIDAJE } \\
\text { TORCUATO PEREZ DE GUZMÁN MOORE }\end{array}$ \\
\hline
\end{tabular}

TEMAS

LECTUAAS HISTORIOGRÁFICA Y HEURISTICA DE LOS CLÁSICOS DE LA SOCIOLOGIA JOSE A. PRADES

\section{PERSONALIA}

EXPERIENCIAS ECOLÓGICAS EN LA INDIA JESÚS VICENS

MARXISMOY AGRICULTURA. CIEN AÑOS DE LA CUESTIÓN AGRARIA DE KAUTSKY FERNANDO OLIVEIRA BAPTISTA

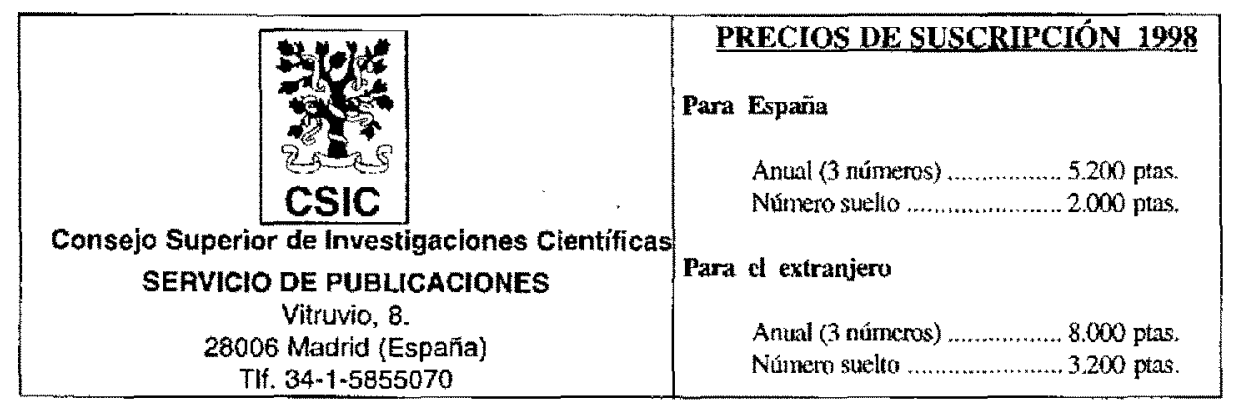

